\title{
Subacute Combined Degeneration from Nitrous Oxide Abuse in a Patient with Pernicious Anemia
}

\author{
Dustin Anderson, Grayson Beecher, Rene van Dijk, Mohammed Hussain, \\ Zaeem Siddiqi, Fang Ba
}

Keywords: Myelopathy, Nitrous oxide

doi:10.1017/cjn.2018.15

Can J Neurol Sci. 2018; 45: 334-335

\section{Case Summary}

A 29-year-old, previously healthy woman presented to the hospital with gradual, progressive lower-extremity weakness and imbalance for a duration of 4 months. On social history, the patient endorsed chronic nitrous oxide abuse through inhalation of pressurized "whippit" canisters typically used in whipped-cream dispensers. She reported consuming in excess of 60 canisters per day $(\sim 80 \mathrm{~g}$ total), with the initiation of her use closely preceding the onset of her symptoms. She denied using any other recreational drugs. Motor examination of the lower extremity revealed increased tone and spasticity, an upper motor neuron pattern of weakness, increased deep tendon reflexes with spread (including crossed adductor reflex), and bilateral Babinski sign. There was a sensory level, with reduced light-touch sensation at the level of the umbilicus and loss of vibratory sensation to the level of the anterior superior iliac spine bilaterally.
Examination of her past blood-work revealed a serum vitamin $\mathrm{B}_{12}$ level that had been serially low $(<75 \mathrm{pmol} / \mathrm{L})$ for nearly 9 months. Screening blood-work at the time of presentation showed a hemoglobin level of $117 \mathrm{~g} / \mathrm{L}$, a platelet count of $243 \times 10^{9} / \mathrm{L}$, and a white blood cell count of $4.0 \times 10^{9} / \mathrm{L}$. Mean corpuscular volume was $90 \mathrm{fl}$. Vitamin $B_{12}$ level remained less than $75 \mathrm{pmol} / \mathrm{L}$ and serum methylmalonic acid level was elevated at $3.7 \mu \mathrm{mol} / \mathrm{L}$ $(0.05-0.27 \mu \mathrm{mol} / \mathrm{L})$. Anti-parietal cell antibodies would later prove to be positive, confirming underlying pernicious anemia. The remainder of her screening blood-work was normal. The patient was admitted with a presumptive diagnosis of myelopathy secondary to $\mathrm{B}_{12}$ deficiency and was initiated on daily intramuscular $B_{12}$ injections.

MRI of the spinal cord (Figures 1A-1B) performed on post-admission day 2 showed bilateral symmetric T2 hyperintensities in the dorsal columns and lateral cortical spinal tracts, in keeping with subacute combined degeneration of the spinal cord.

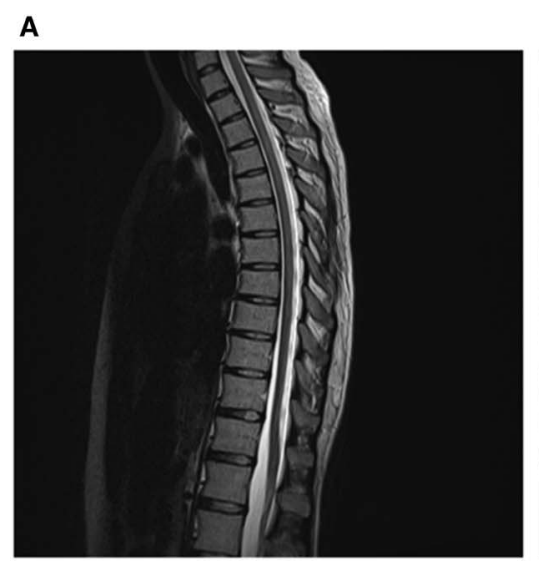

B

Figure 1: Nitrous oxide-induced myelopathy. Sagittal T2 MRI of the thoracic spinal cord (A) demonstrating T2 hyperintensities longitudinally through the spinal cord. Axial T2 MRI of the thoracic cord at the level of T4 (B) showing bilateral symmetric T2 signal change in the dorsal columns and lateral cortical spinal tracts.

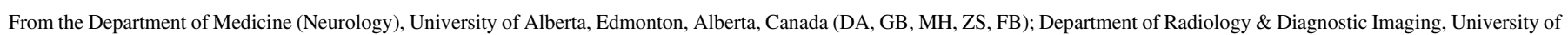
Alberta, Edmonton, Alberta, Canada (RvD).

Received January 15, 2018. Final Revisions Submitted March 6, 2018. Date of Acceptance February 5, 2018.

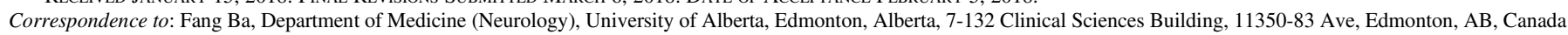
T6G 2G3. Email: fb@ualberta.ca
} 
Despite normalization of her vitamin $\mathrm{B}_{12}$ levels $(696 \mathrm{pmol} / \mathrm{L}$ on postadmission day 5), the patient did not show any clinical improvement. She was discharged against medical advice on post-admission day 10 and has since been lost to follow-up.

Nitrous oxide is a commonly used inhaled anesthetic, known for its mood-elevating properties. ${ }^{1}$ Nitrous oxide abuse can result in myelopathy, ${ }^{2}$ neuropathy, ${ }^{3}$ or myeloneuropathy. ${ }^{4,5}$ MRI of the spinal cord typically reveals non-enhancing T2 hyperintensity along the posterior columns and corticospinal tracts and is often longitudinally extensive. ${ }^{6}$ The mechanism by which nitrous oxide mediates neurotoxicity is thought to be by the irreversible oxidization of cobalt ions in vitamin $B_{12}$, resulting in its inactivation., Consequently, homocysteine conversion to methionine via methionine synthetase is impaired. Methionine is necessary in the maintenance and production of myelin, and its reduced availability leads to preferential degeneration of the myelinated posterior and lateral columns of the spinal cord. Nitrous oxide use may precipitate significant clinical deficits in patients with previously subclinical $\mathrm{B}_{12}$ deficiency, as was seen in our patient. ${ }^{8}$ Treatment of neurological complications from nitrous oxide abuse includes cessation of nitrous oxide use and vitamin $\mathrm{B}_{12}$ replacement therapy. ${ }^{7}$

\section{DisCLOSURES}

The authors have nothing to disclose.

\section{Statement of Authorship}

DA performed the patient's clinical assessment, drafted the manuscript, and created the figure. GB assisted in the patient's clinical assessment and drafted the manuscript and figure legend. RvD reported the imaging findings, provided the figure images, and edited the manuscript. $\mathrm{MH}, \mathrm{ZS}$, and $\mathrm{FB}$ performed clinical assessments, provided patient care, and performed critical revisions of the manuscript for intellectual content.

\section{REFERENCES}

1. Louis-Ferdinand RT. Myelotoxic, neurotoxic and reproductive adverse effects of nitrous oxide. Adverse Drug React Toxicol Rev. 1994;13:193-206.

2. Pema PJ, Horak HA, Wyatt RH. Myelopathy caused by nitrous oxide toxicity. AJNR Am J Neuroradiol. 1998;19: 894-896.

3. Layzer RB, Fishman RA, Schafer JA. Neuropathy following abuse of nitrous oxide. Neurology. 1978;28:504-6.

4. Layzer RB. Myeloneuropathy after prolonged exposure to nitrous oxide. Lancet. 1978;2:1227-30.

5. Vishnubhakat SM, Beresford HR. Reversible myeloneuropathy of nitrous oxide abuse: serial electrophysiological studies. Muscle Nerve. 1991;14:22-6.

6. Renard D, Dutray A, Remy A, Castelnovo G, Labauge P. Subacute combined degeneration of the spinal cord caused by nitrous oxide anaesthesia. Neurol Sci. 2009;30(1):75-6.

7. Thompson AG, Leite MI, Lunn MP, Bennett DL. Whippits, nitrous oxide and the dangers of legal highs. Pract Neurol. 2015; 15:207-9.

8. Singer MA, Lazaridis C, Nations SP, Wolfe GI. Reversible nitrous oxide-induced myeloneuropathy with pernicious anemia: case report and literature review. Muscle Nerve. 2008; 37(1):125-9. 